\title{
A Novel Module Independent Straight Line-Based Fast Maximum Power Point Tracking Algorithm for Photovoltaic Systems
}

\author{
Anjan Debnath, Temitayo O. Olowu, Imtiaz Parvez ${ }^{D}$, Md Golam Dastgir and Arif Sarwat * \\ Electrical and Computer Engineering, Florida International University, 10555 W Flagler St, \\ Miami, FL 33174, USA; adebn001@fiu.edu (A.D.); tolow003@fiu.edu (T.O.O.); iparv001@fiu.edu (I.P.); \\ mdast001@fiu.edu (M.G.D.) \\ * Correspondence: asarwat@fiu.edu
}

Received: 17 May 2020; Accepted: 12 June 2020; Published: 22 June 2020

\begin{abstract}
The maximum power point tracking (MPPT) algorithm has become an integral part of many charge controllers that are used in photovoltaic (PV) systems. Most of the existing algorithms have a compromise among simplicity, tracking speed, ability to track accurately, and cost. In this work, a novel "straight-line approximation based Maximum Power Point (MPP) finding algorithm" is proposed where the intersections of two linear lines have been utilized to find the MPP, and investigated for its effectiveness in tracking maximum power points in case of rapidly changing weather conditions along with tracking speed using standard irradiance and temperature curves for validation. In comparison with a conventional Perturb and Observe $(P \mathcal{E} O)$ method, the Proposed method takes fewer iterations and also, it can precisely track the MPP s even in a rapidly varying weather condition with minimal deviation. The Proposed algorithm is also compared with P\&O algorithm in terms of accuracy in duty cycle and efficiency. The results show that the errors in duty cycle and power extraction are much smaller than the conventional $P \mathcal{E} O$ algorithm.
\end{abstract}

Keywords: linear approximation; MPPT algorithm; duty cycle; global horizontal irradiance; mathematical modeling

\section{Introduction}

Electricity generation from renewable energy sources has consistently increased over the past decade, with the largest percentage of renewable energy sources integrated being photovoltaic (PV) systems [1-5]. There has been a consistent increase in installed PV capacity globally which has lead to a corresponding increase in power generation from PV systems as shown in Figure 1 [6].

The massive integration of PV systems has also been aided by the declining cost of PV modules and improvement in their efficiencies [7]. Other than grid-tied PV systems, the use of PV modules has been extended to various applications such as rooftop solar power supply for residential homes, mobile charging systems, wearable devices, standalone PV arrays as car parks and electric vehicle charging stations, remote weather stations, international space station, and robots for space exploration.

In contrast to PV systems, Solar Thermal Plants (STPs) allow power to be generated by concentrating solar radiation which causes a very high temperature. The heat produced is subsequently used to convert water to steam which then used to turn power turbines for electricity generation. STPs are oriented to allow maximum tracking of the sun's insolation. The plants usually consist of reflectors and receivers. The reflectors (which are typically mirrors) are used to capture and concentrate the sun's light rays onto the receivers. The heat absorbed by the receivers is used to convert water to steam in order to drive the conventional steam turbine generators. It is of uttermost importance for the 
reflectors used in solar thermal plants to constantly track the movement of the sun in order to ensure maximum extraction of solar rays in order to maximize the efficiency of the plant [8-10]. In comparison with PV systems, Thermal Energy Storage (TES) technologies can be used to store energy for use at night, during severe cloud coverage, or periods with little or no sunlight. This allows STPs to be more dispatchable and achieved a higher capacity factor compared to PV. On the other hand, the decking cost of PV systems makes them cheaper than the STPs. A report by [11] suggests that STP technology might in the future help to increase the amount of PV penetration in the grid rather than being a direct competitor or alternative.

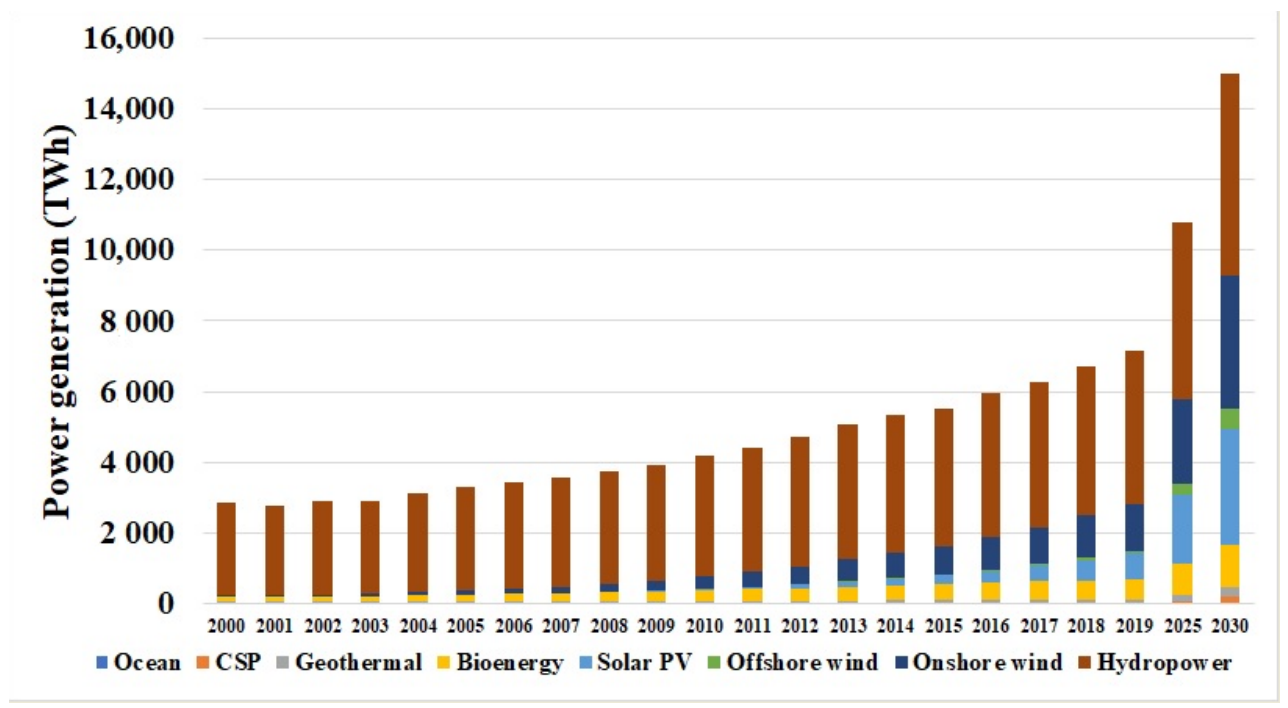

Figure 1. Power generation from renewable energy sources globally [6].

Due to the relatively low efficiency of PV systems compared to conventional power sources such as coal, diesel, or gas-fired plants, extraction of the maximum power per unit PV module becomes imperative. Maximum Power Point Tracking (MPPT) algorithms are developed to allow PV systems to operate at their maximum power under prevailing weather conditions [12-14]. The power generation from PV systems largely depends on the global horizontal irradiance and the atmospheric (consequently module) temperature. These parameters are stochastic in nature which means an accurate tracking system (simply called the Maximum Power Point Tracking (MPPT) system) to extract the maximum power out of the PVs is necessary. Several techniques and algorithms have been proposed for MPPT applications. These techniques and algorithms include the machine learning [15,16], hill climbing method [17-21], incremental conductance technique [22-25], Perturb and Observe [26-28], fractional open circuit voltage [29-31], fractional short circuit current [32-34], and fuzzy logic-based MPPT algorithms [35-38] amongst others. These algorithms aim to achieve high efficiency, fast-tracking speed, reduced steady-state oscillations, and reduced complexity in hardware implementation [38]. Out of these algorithms, the Perturb and Observe $(\mathrm{P} \& \mathrm{O})$ algorithm, Incremental Conductance, and Fractional Open Circuit algorithm are most popular because of their simplicity. The PEO MPPT algorithm has dual shortcomings: enormous power loss due to large oscillations and deflection of tracking under rapid weather conditions. The large power loss can be minimized by choosing a small step size around the Maximum Power Point (MPP). However, the convergence speed has to be sacrificed [39]. The main drawbacks of Incremental and Conductance algorithms are the complex circuitry because of the derivative finding and choice of perturbation extent. The fractional open circuit based algorithm depends on the open circuit voltage of the panel, so at every change of irradiance, there is a temporary power loss due to the measurement of $V_{O C}$. Moreover, it is not module independent since the $V_{O C}$ value has to be known prior to the application of the algorithm. Fractional short circuit current algorithm has the same issue as the fractional open circuit voltage. The algorithm is required to know the characteristics of the PV module and manufacturing specifications which makes it module dependent 
and less efficient. Machine learning (such as ANN) based MPPT algorithms are dependent on features (weather data) to generate the desired duty cycle for finding the MP point and one of the most common features is irradiance which requires costly sensors to measure. Though these algorithms are fast in finding MPPs, they are not cost-effective. Moreover, they require a lot of data to train which is the most important part of those models to demonstrate good accuracy. Therefore, it can not be generalized for any module. The PV module characteristics also change with time which necessitates the need for periodic training of the ANN-based controller to accurately track the MPP.

It is obvious that selecting an MPPT algorithm for many applications is usually a trade-off between efficiency, complexity, speed, cost, and ease of hardware implementation. This paper proposes a novel MPPT algorithm where the Maximum Power Point is acquired by the intersection of two linear lines which are tangents to the power vs voltage curve of the photovoltaic module. The major contributions of this paper are the following:

(i) Number of iterations in reaching the MPP s are way less than conventional MPPT algorithm

(ii) Reduction of oscillations around the MPP is much better than conventional, less than $0.03 \%$

(iii) Module independence, therefore the algorithm can be used in any PV modules without knowing the module data

(iv) Highly efficient and easily implementable

MATLAB/SIMULINK environment is used for the simulation and verification of the Proposed algorithm. BP Solar BP SX 150S PV module is chosen in the MATLAB simulation model. The module is made of 72 multi-crystalline silicon solar cells in series and provides $150 \mathrm{~W}$ of nominal maximum power [40]. Table 1 shows the electrical parameters of the module:

Table 1. Electrical characteristics of PV Module Specifications.

\begin{tabular}{cc}
\hline Maximum Power $\left(P_{M A X}\right)$ & $150 \mathrm{~W}$ \\
Voltage at $P_{M A X}\left(V_{M P}\right)$ & $34.5 \mathrm{~V}$ \\
Current at $P_{M A X}\left(I_{M P}\right)$ & $4.35 \mathrm{~A}$ \\
Open Circuit Voltage $\left(V_{O C}\right)$ & $43.5 \mathrm{~V}$ \\
Short Circuit Current $\left(I_{S C}\right)$ & $4.75 \mathrm{~A}$ \\
\hline
\end{tabular}

The rest of this paper is structured as follows: Section 2 presents the development of Proposed algorithm and description of the PEO; Section 3 represents simulation results using the Proposed algorithm under slow and fast varying weather conditions, a comparison between the Proposed algorithm with the $P \mathcal{E O}$ algorithm and validation of the Proposed algorithm using the CENELEC EN50530 standard test procedures; Section 4 concludes this paper.

\section{Development of Proposed Algorithm and Description of the P\&O}

Several MPPT algorithms have been proposed in literature. The P\&O, which is one of the widely used MPPT algorithms is selected as a baseline to compare the performance of the Proposed algorithm. The detailed formulation and modeling of the Proposed algorithm and a brief description of the $P \mathcal{E} O$ is as presented the following subsection.

\subsection{Development of the Proposed Algorithm}

Figure 2, the flowchart of the Proposed algorithm, depicts the construction of the algorithm. In developing the algorithm, a straight line approximation technique is utilized which is based on the P-V curve shapes. There is no evidence of significantly different P-V curve shape other than an inverted tilted ' $V$ '. So, the Proposed algorithm can be employed universally for a controller coupled with any kind of P-V panel without taking the panel's preset values. The details of the flowchart are depicted in the following: 
1. At first, it senses voltage $V_{1}$ and $I_{1}$ by voltage and current sensors, respectively, and measured the power, $P_{1}$. Then the voltage is perturbed by a small amount, $\mathrm{b}$ and another voltage, $V_{2}$, is taken. The the power, $P_{2}$ is measured .

2. If $\Delta P=P_{2}-P_{1}>0$, the operating point is at the left of MPP, else the operating point is at the right of the MPP.

3. Afterwards, the algorithm perturbs the voltage by a bigger step size $\mathrm{c}$ and senses the new voltage, $V_{3}$ followed by a small perturbation $\mathrm{b}$. Then it measures voltage $V_{4}$ and calculates $\Delta$ $P=\left(P_{4}-P_{3}\right)$.

4. If $\Delta P<0$, the desired four points $\left(V_{1}, P_{1}\right),\left(V_{2}, P_{2}\right)$ and $\left(V_{3}, P_{3}\right),\left(V_{4}, P_{4}\right)$ are found to draw the two straight lines. The algorithm will find then the intersecting point $V_{i}$ by solving the equations. The intersecting point should be close to the MPP . If $\Delta P>0$, step 3 needs to be repeated until $\Delta$ $P<0$ is fulfilled.

5. The point $V_{i}$ is not the desired MPP, rather it is very close to MPP. To track the MPP, the algorithm will perturb the voltage by a small amount $\mathrm{b}$ and calculate $\Delta P$ again.

6. If $\Delta P<0$, the operating point is at the right side of MPP, else the operating point is at the left side of the MPP.

7. If the operating point lies at the left side of $\operatorname{MPP}(\Delta P>0)$, the algorithm will keep on perturbing the voltage by a small amount ' $\mathrm{b}$ ' until $\Delta P<0$ is satisfied. Once it reaches to that condition, the algorithm stops and $P_{i i i}$ will be the desired MPP. However, if it starts from the right side of MPP $(\triangle P<0)$, the algorithm will then keep on perturbing the voltage by a small amount ' $\mathrm{b}$ ' to the left side. Once $\Delta P>0$ is satisfied, the algorithm stops and $P_{i i i}$ is the desired MPP.

\subsubsection{Mathematical Model of the Proposed Algorithm}

In the developed method, MPP can be tracked very quickly and this operation is graphically illustrated in Figure 3. To understand the Proposed algorithm, let us take the operating point $P_{1}$ which is at the left side of MPP. By a small perturbation of voltage, another point $P_{2}$ can be found as: $\Delta P=P_{2}-P_{1}>0$

Now, by straight a line approximation, we can write an equation:

$$
P=m_{1} V+C_{1}
$$

where:

$$
\begin{gathered}
m_{1}=\left(P_{2}-P_{1}\right) /\left(V_{2}-V_{1}\right) \text { and } \\
C_{1}=\left(V_{1} P_{2}-V_{2} P_{1}\right) /\left(V_{2}-V_{1}\right)
\end{gathered}
$$

Now by taking another two points in the right side of MPP where $\Delta P=P_{4}-P_{3}<0$ does match, another equation can be written also.

$$
P=m_{2} V+C_{2}
$$

where:

$$
\begin{aligned}
& m_{2}=\left(P_{4}-P_{3}\right) /\left(V_{4}-V_{3}\right) \text { and } \\
& C_{2}=\left(V_{3} P_{4}-V_{4} P_{3}\right) /\left(V_{3}-V_{4}\right)
\end{aligned}
$$

By solving Equations (1) and (2), the intersecting point $V_{A}$ can be found as follows:

$$
\begin{gathered}
m_{1} V+C_{1}=m_{2} V+C_{2} \text { and } \\
V_{A}=\left(C_{2}-C_{1}\right) /\left(m_{1}-m_{2}\right)
\end{gathered}
$$


After getting $V_{A}$ which is very near to MPP, the algorithm would reach MPP very fast as depicted in Figure 3.

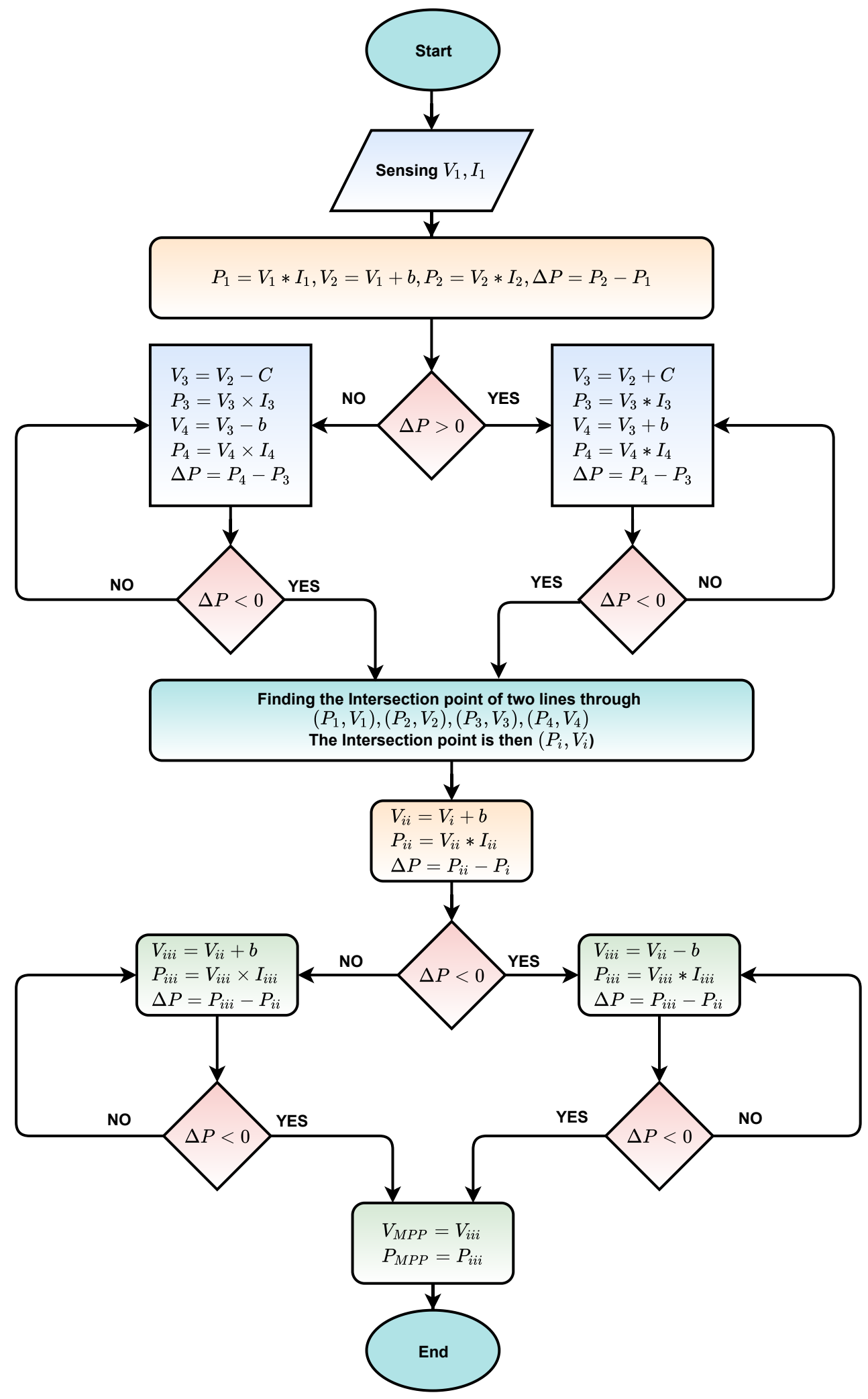

Figure 2. Flowchart of the Proposed algorithm. 


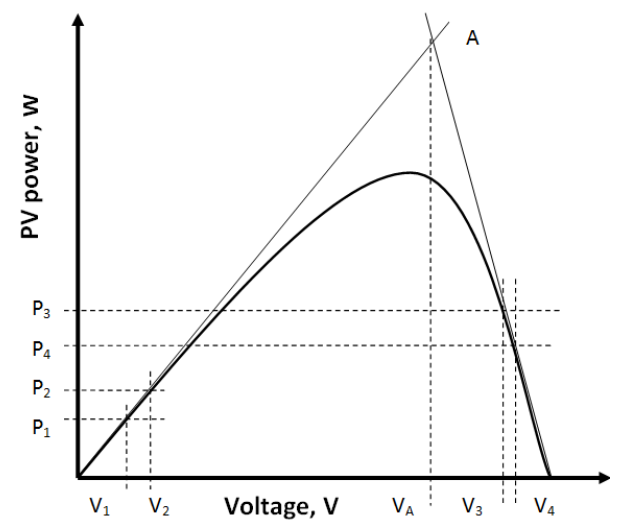

Figure 3. Straight line approach to find the MPP.

\subsubsection{Response of the Proposed Algorithm When Irradiance Increases Rapidly}

Here, the reaction towards rapidly changing weather conditions has been analyzed. In Figure 4, it is shown how the normal $P \mathcal{E} O$ method fails for a rapid variation in irradiance. Starting from an operating point located at $P_{1}$ (right side of MPP) we see, after a little perturbation, the new value is $P_{2}$. If the irradiance does not change during the perturbation, then $P_{2}$ will be lying on the same curve with $G_{1}, I_{1}$. So:

$$
\begin{aligned}
& \Delta P=P_{2}-P_{1}<0 \\
& \Delta V=V_{k}-V_{k-1}>0
\end{aligned}
$$

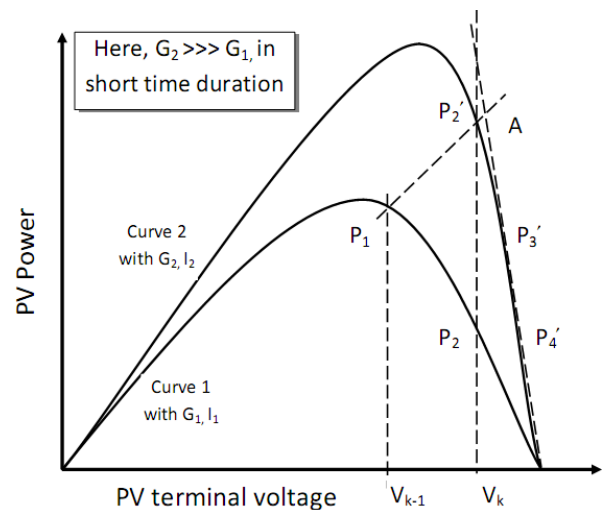

Figure 4. Response of Proposed method for rapidly increasing irradiance.

Consequently, the $P \mathcal{E} O$ algorithm will drive the operating point leftward which would be the correct direction. However, if the irradiance changes rapidly during the perturbation, then $P_{2}$ should lie on the $G_{2}$ curve at corresponding $V_{K}$. Let us call it $P_{2}^{\prime}$.

$$
\begin{aligned}
& \Delta P=P_{2}^{\prime}-P_{1}>0 \\
& \Delta V=V_{k}-V_{k-1}>0
\end{aligned}
$$

Accordingly, the $P \mathcal{E} O$ algorithm would drive the operating point into the right side which is the wrong direction even though it should have driven it to the left, whereas, the developed method would draw the straight line passing through these two points $P_{1}, P_{2}^{\prime}$ and will take another two points $P_{3}^{\prime}, P_{4}^{\prime}$ on the $I_{2}$ curve and draw the straight line as depicted in Figure 4. After calculating the intersection point, $V_{A}$ of these two straight lines, the algorithm would then drive the operating point to leftward to reach the MPP on $G_{2}$ curve.

\subsection{The Conventional PEO Algorithm}

In the conventional $P \mathcal{E} O$ algorithm, duty signal is perturbed till the operating point converges at the MPP. The algorithm compares the voltage and power at two consecutive samples. A small voltage 
perturbation is performed, if the change of power is positive, the perturbation is continued in the same direction and for a negative change in power, the perturbation is reversed in order to reach the MPP. By this approach, the whole P-V curve is checked using fixed perturbations to find the MPP. If the perturbation size is small, the algorithm takes a longer time in reaching the MPP with a high level of accuracy and vice versa. A large perturbation size could cause the algorithm to produce steady-state oscillations around the MPP [41]. Figure 5 illustrates the steps required in determining the MPP using the $P \mathcal{E} O$ approach.

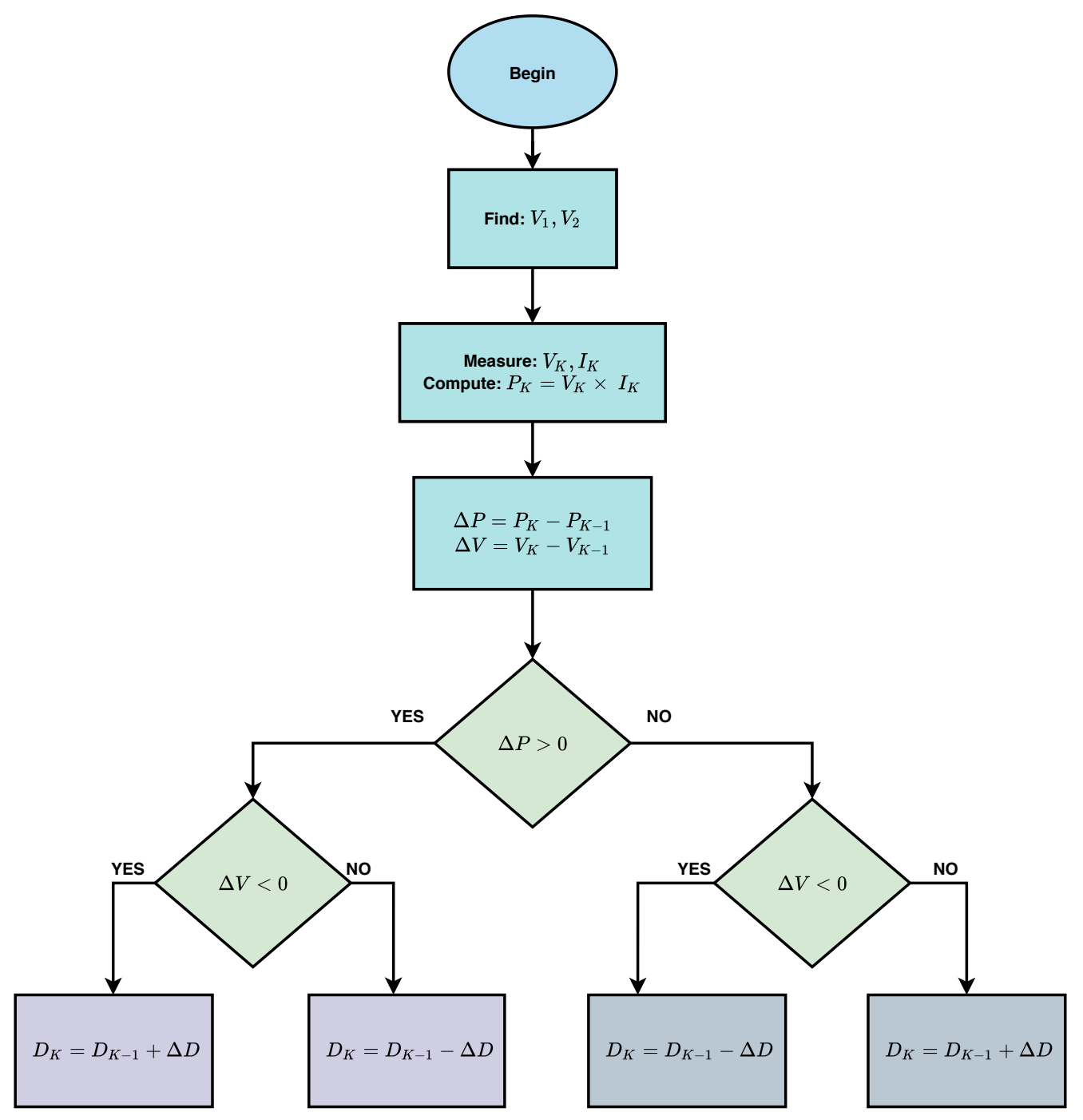

Figure 5. Flowchart of the conventional PEO Algorithm.

\section{Simulation Results Using the Proposed Algorithm}

In this section, simulation was conducted under normal and rapid weather conditions to test the response of the Proposed algorithm. Then comparison was made between $P \mathcal{E} O$ and Proposed algorithm in terms of the total number of iterations in reaching the MPP. After that, the percentage of error in duty signal and power corresponding to the MPPs was compared. Finally, the validation of the Proposed algorithm was performed using standard irradiance curves.

\subsection{Simulation Results under Normal and Rapid Weather Conditions}

In order to investigate the responses of the algorithm, practical irradiance data was taken a for a sunny day and a cloudy day for $12 \mathrm{~h}$ period from 6 a.m. to 6 p.m. This Global Horizontal Irradiance 
(GHI) is plotted for a sunny day and cloudy day as shown in Figure $6 a, b$ respectively in order to certify the efficacy of the Proposed MPPT algorithm.

Figure 7a-c, illustrate the accuracy of the Proposed algorithm for sunny and cloudy weather conditions. In Figure 7a,b, the module power vs module voltage graph is plotted for when irradiance was varying for a particularly sunny day and cloudy day respectively. The red dots shown in Figure 7a,b, are the exact MPPs and the green curve is the output of the developed algorithm. Itis very clear from those figures that the Proposed algorithm accurately identified the exact MPPs. The cloudy day irradiance shown in Figure 6a changed very rapidly; nonetheless, the Proposed algorithm was able to determine the MPPs (red dots) very successfully which is very clear from Figure $7 \mathrm{~b}$. Figure $7 \mathrm{c}$ shows how the module power could be varied just by varying the duty cycle which ensured that the operating point of the PV panel could be varied by changing the duty ratio.

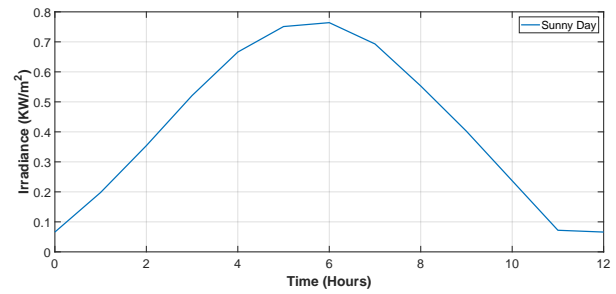

(a)

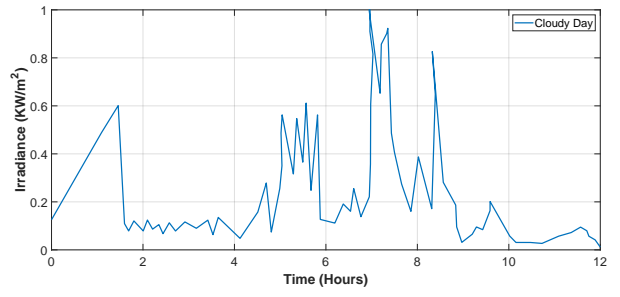

(b)

Figure 6. (a) Sunny Day Irradiance Data from 6 a.m. to 6 p.m. (b) Cloudy Day Irradiance Data from 6 a.m. to 6 p.m.

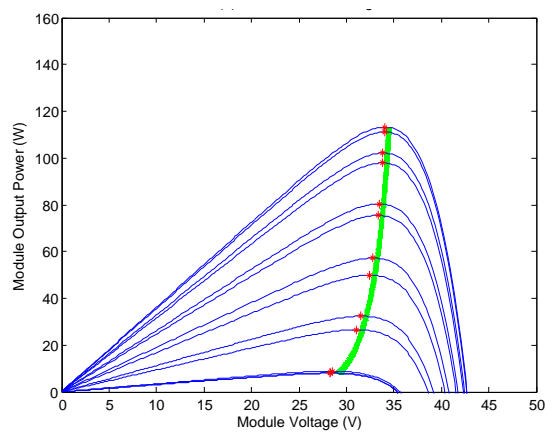

(a)

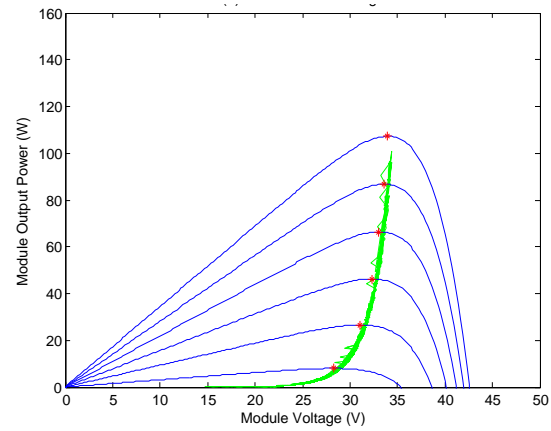

(b)

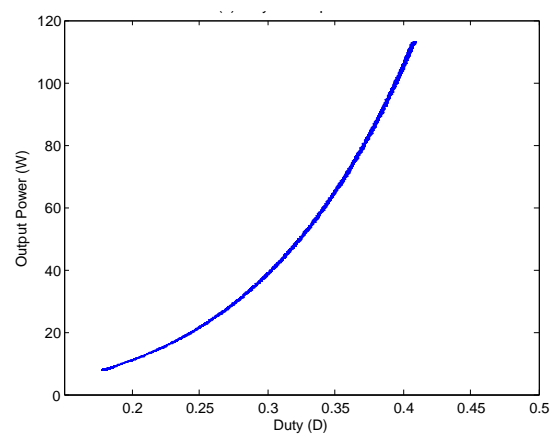

(c)

Figure 7. (a) Panel voltage vs. power for a sunny day (b) Panel voltage vs Power for a Cloudy Day (c) Duty vs. Output Power. 


\subsection{Comparison of the Proposed Algorithm with Conventional Perturb and Observe Algorithm}

Here, the number of iterations to reach the MPP was compared between the developed method and Perturb and Observe method for the following conditions:

Irradiance, $G=1 \mathrm{KW} / \mathrm{m}^{2}$ Temperature, $T_{a} C=25{ }^{\circ} \mathrm{C}$

Operating point, $\mathrm{Va}=5 \mathrm{~V}$ (left side of MPP )

When the operating point lay at the left of MPP, Table 2 shows a comparison between the number of iterations used by the Proposed and PEO algorithm, where $N_{o p-I p}$ is the number of iterations from operating point to intersection point and $N_{I p-M P P}$ is the number of iterations from intersection point to MPP. The number of iterations used by the developed algorithm was much less than that of the PEO method. Initially, the developed method had big steps $(2 \mathrm{~V})$ in order to get the intersection point $(32.2346 \mathrm{~V})$ of two straight lines and took 15 iterations. The intersection point was close to the MPP as mentioned earlier. From MPP intersection point to the, the algorithm took 22 iterations since it went with small steps $(0.1 \mathrm{~V})$. The small steps after finding the intersection point not only made sure of small oscillations around MPP but also ensured high efficiency.

When the operating point lay at the right side of MPP, Table 3 data confirms again that the number of iterations of the Proposed algorithm was much smaller than the conventional PEO method. of MPP).

Irradiance, $G=1 \mathrm{KW} / \mathrm{m}^{2}$ Temperature, $\mathrm{TaC}=25^{\circ} \mathrm{C}$ Operating point, $\mathrm{Va}=40 \mathrm{~V}$ (right side

Table 2. Number of iterations comparison between developed and $P \mathcal{E} O$ algorithm when the operating point lies at left of MPP.

\begin{tabular}{|c|c|c|c|}
\hline & $P \mathcal{E O}($ Step Size $=0.1)$ & Proposed $($ Step Size $=2,0.1)$ & Exact Value \\
\hline MPP Voltage & 34.6 & 34.5346 & 34.5 \\
\hline MPP Power & 149.9709 & 149.9825 & 149.9858 \\
\hline Intersection Voltage & NA & 32.2346 & NA \\
\hline$N_{o p-I p}$ & NA & 15 & NA \\
\hline$N_{I p-M P P}$ & NA & 22 & NA \\
\hline Total of iterations & 296 & 37 & NA \\
\hline
\end{tabular}

Table 3. No. of iterations comparison between developed and $P \mathcal{E} O$ when the operating point lies at right of MPP.

\begin{tabular}{|c|c|c|c|}
\hline & $P \mathcal{E} O($ Step Size $=0.1)$ & Proposed $($ Step Size $=2,0.1)$ & Exact Value \\
\hline MPP Voltage & 34.6 & 34.3498 & 34.5 \\
\hline MPP Power & 149.9709 & 149.9784 & 149.9858 \\
\hline Intersection Voltage & NA & 32.2346 & NA \\
\hline$N_{o p-I p}$ & NA & 3 & NA \\
\hline$N_{I p-M P P}$ & NA & 29 & NA \\
\hline Total of iterations & 54 & 32 & NA \\
\hline
\end{tabular}

\subsection{Comparison between Proposed and Perturb and Observe Algorithm in Terms of Duty and Maximum} Power Point

Here, the irradiance and temperature were varied to analyze the performance and compare the two algorithms. It is very apparent from Table 4 that the Proposed method obtained the duty cycles and maximum power points much closer to the exact duty cycle and maximum power points than the Perturb and Observe method under varying weather conditions which secured better efficiency.

The comparison in terms of percentage error in duty cycle and percentage error in finding MPPs are illustrated in Figure 8a,b. It is evident in Figure 8a that the Proposed algorithm had a very small 
error in finding the correct duty cycle under varying irradiance conditions. The error was less than $\pm 0.5 \%$ whereas the Perturb and Observe algorithm had more than $\pm 1 \%$ error in finding the correct duty cycle. The similar scenario was observed in Figure $8 \mathrm{~b}$ as well where the percentage error in finding the Maximum Power Point under varying irradiance conditions was less than $0.03 \%$ for the Proposed algorithm whereas it was more than $0.23 \%$ in the case of the Perturb and Observe method.

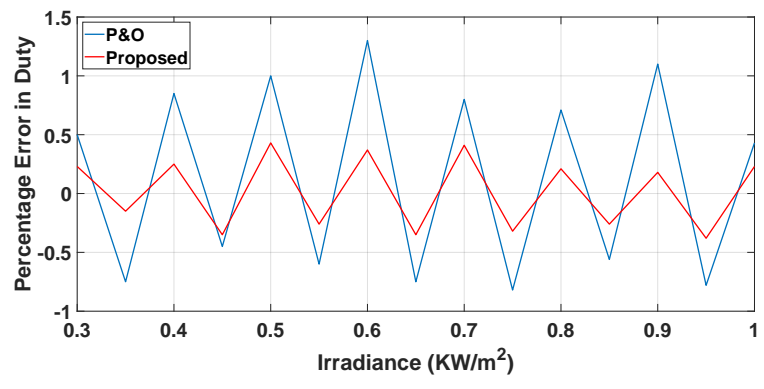

(a)

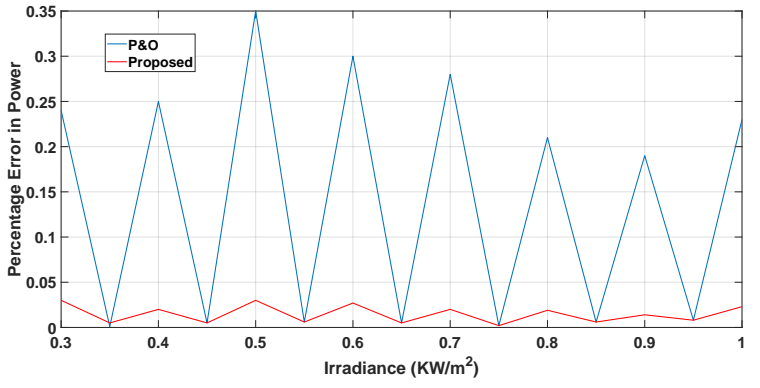

(b)

Figure 8. (a) Comparison of percentage of error in duty cycle under $25^{\circ} \mathrm{C}$ between Proposed and conventional Perturb and Observe (P\&O) algorithm (b) Comparison of percentage of error in Maximum Power Point under $25^{\circ} \mathrm{C}$ between Proposed and conventional $P \mathcal{E O}$ algorithm.

Table 4. Comparison of duty cycle and maximum power between Proposed and PEO algorithm at different irradiance and temperature.

\begin{tabular}{ccccccc}
\hline $\mathbf{G}$ and $\mathbf{T}\left(\mathbf{k W} / \mathbf{m}^{\mathbf{2}},{ }^{\circ} \mathbf{C}\right)$ & $\boldsymbol{D}_{\text {exact }}$ & $\boldsymbol{D}_{\text {Proposed }}$ & $\boldsymbol{D}_{\boldsymbol{P \& O}}$ & $\boldsymbol{P}_{\text {exact }}$ & $\boldsymbol{P}_{\text {Proposed }}$ & $\boldsymbol{P}_{\boldsymbol{P \& O}}$ \\
\hline$(0.3,0)$ & 0.3177 & 0.3201 & 0.3100 & 46.8442 & 46.8059 & 46.4333 \\
$(0.3,10)$ & 0.3228 & 0.3200 & 0.3100 & 44.8187 & 44.7739 & 43.8932 \\
$(0.3,20)$ & 0.3275 & 0.3280 & 0.3310 & 42.7801 & 42.7802 & 42.7203 \\
$(0.5,0)$ & 0.3725 & 0.3720 & 0.3730 & 80.4209 & 80.4200 & 80.4165 \\
$(0.5,10)$ & 0.3774 & 0.3780 & 0.3790 & 77.1584 & 77.1546 & 77.1326 \\
$(0.5,20)$ & 0.3824 & 0.3820 & 0.3790 & 73.8728 & 73.8702 & 73.7657 \\
$(0.8,10)$ & 0.4314 & 0.4320 & 0.4270 & 126.4301 & 126.4219 & 126.1785 \\
$(0.8,20)$ & 0.4367 & 0.4350 & 0.4390 & 121.3375 & 121.3139 & 121.2492 \\
$(0.8,30)$ & 0.4415 & 0.4420 & 0.4390 & 116.2146 & 116.2139 & 116.1323 \\
$(1.0,20)$ & 0.4627 & 0.4620 & 0.4630 & 153.1360 & 153.1256 & 153.1357 \\
$(1.0,30)$ & 0.4683 & 0.4680 & 0.4690 & 146.8280 & 146.8288 & 146.8160 \\
$(1.0,40)$ & 0.4734 & 0.4720 & 0.4750 & 140.4862 & 140.4611 & 140.4538 \\
$(1.2,20)$ & 0.4848 & 0.4850 & 0.4870 & 184.8904 & 184.8890 & 184.7909 \\
$(1.2,30)$ & 0.4897 & 0.4890 & 0.4870 & 177.4167 & 177.4042 & 177.2795 \\
$(1.2,40)$ & 0.4948 & 0.4950 & 0.4990 & 169.9001 & 169.9017 & 169.6730 \\
\hline & & & & & &
\end{tabular}

\subsection{Validation of the Proposed MPPT Algorithm}

In order to validate the Proposed algorithm, the standard test irradiance profile (according to CENELEC EN50530) was used [42,43] which is shown in Figures 9a-12a. Figures 9a-12c show the performance of the developed algorithm under irradiation ramps with very steep gradients of $0.5,5$, 20,50 and $100 \mathrm{~W} / \mathrm{m}^{2} / \mathrm{s}$. From these figures, it can be seen that the quality of the MPP tracking was very good and it was accurate with all gradients. The figures show that the current always tracked the irradiance changes accurately, whereby the voltage was either lagging or leading the MPP by a very small amount. This can be explained by the fact that the current was linearly proportional to irradiance and it was almost impossible to detect the exact MPP voltage because the algorithm had to use an epsilon(stopping condition when close to MPP) value which was less than a preset value (the difference between exact $V_{M P P}$ and estimated $V_{M P P}$ which was very close to exact MPP but not equal) 
to get very close to exact $V_{M P P}$. Therefore the detected $V_{M P P}$ points stayed either before or after the exact $V_{M P P}$ point, however very close.

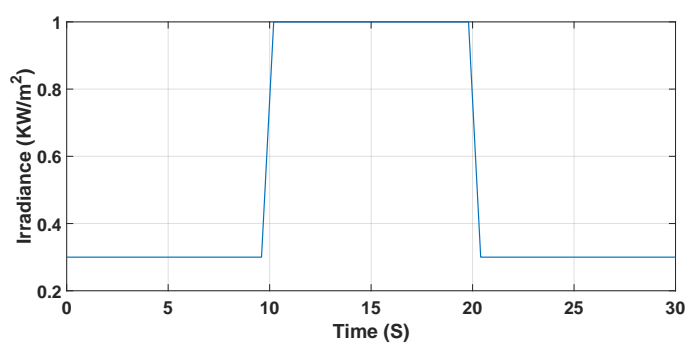

(a)

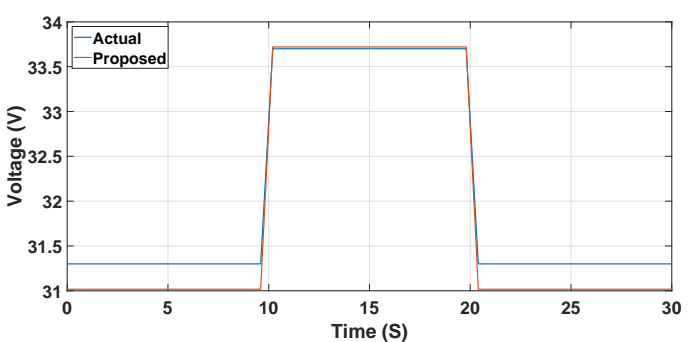

(b)

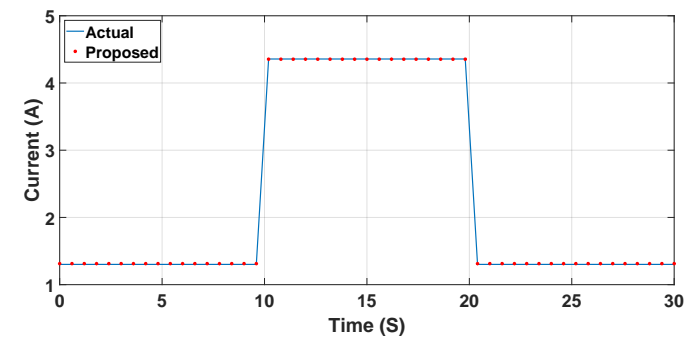

(c)

Figure 9. (a) Very steep gradient (b) accuracy of the Proposed algorithm in finding $V_{m p p}$ at very steep gradient (c) accuracy of the Proposed algorithm in finding $I_{m p p}$ at very steep gradient.

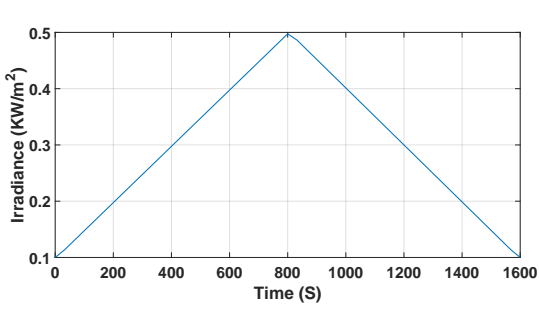

(a)

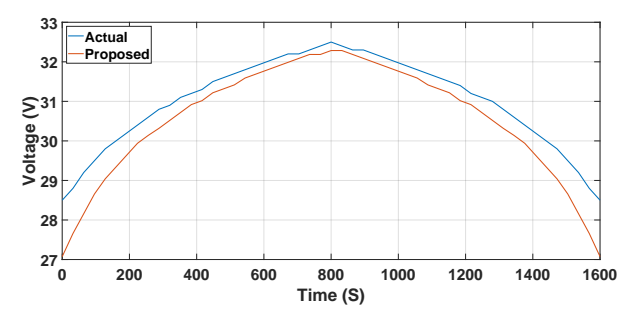

(b)

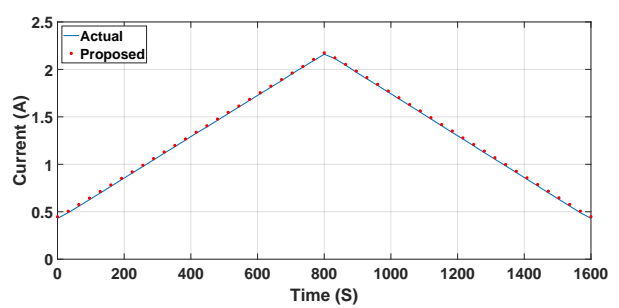

(c)

Figure 10. (a) Irradiance with gradient of $0.5 \mathrm{~W} / \mathrm{m}^{2} / \mathrm{s}$ (b) accuracy of Proposed algorithm in finding $V_{M P P}$ at $0.5 \mathrm{~W} / \mathrm{m}^{2} / \mathrm{s}$ gradient (c) accuracy of the Proposed algorithm in finding $I_{M P P}$ at $0.5 \mathrm{~W} / \mathrm{m}^{2} / \mathrm{s}$ gradient. 


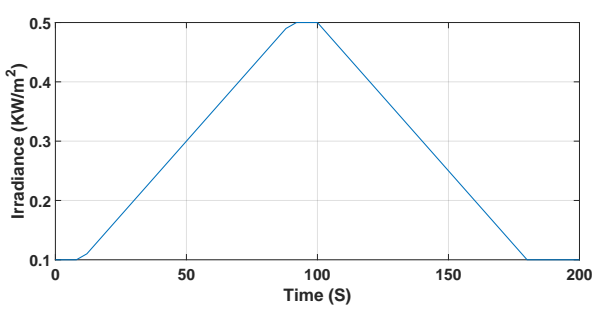

(a)

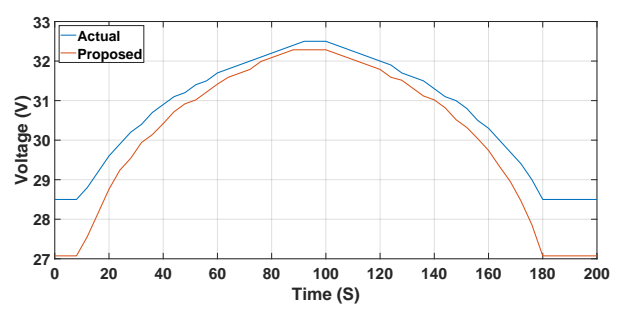

(b)

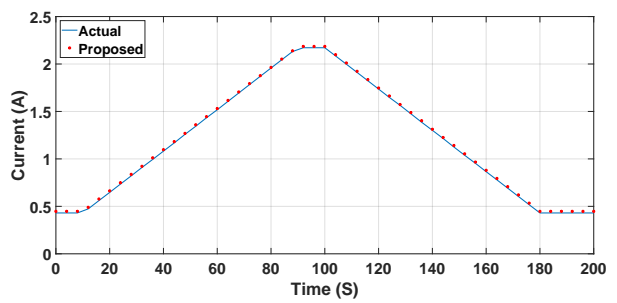

(c)

Figure 11. (a) Irradiance at a gradient of $5 \mathrm{~W} / \mathrm{m}^{2} / \mathrm{s}$ (b) accuracy of the Proposed algorithm in finding $V_{m p p}$ at $5 \mathrm{~W} / \mathrm{m}^{2} / \mathrm{s}$ gradient (c) accuracy of the Proposed algorithm in finding $I_{m p p}$ at $5 \mathrm{~W} / \mathrm{m}^{2} / \mathrm{s}$ gradient.

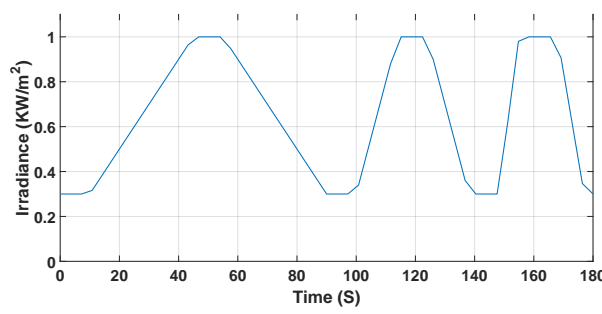

(a)

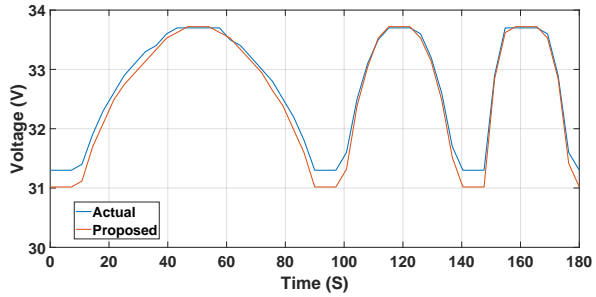

(b)

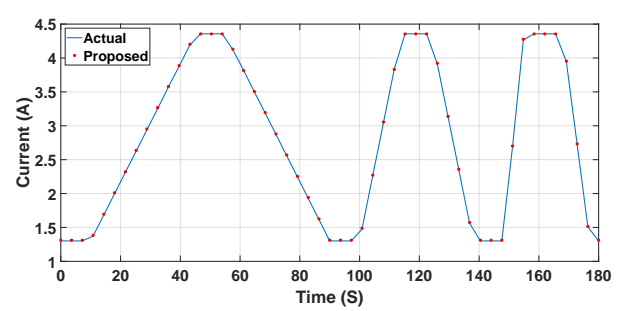

(c)

Figure 12. (a) Irradiance at gradients of $20,50,100 \mathrm{~W} / \mathrm{m}^{2} / \mathrm{s}$ (b) accuracy of the Proposed algorithm in finding $V_{m p p}$ at gradients of $20,50,100 \mathrm{~W} / \mathrm{m}^{2} / \mathrm{s}$ (c) accuracy of the Proposed algorithm in finding $I_{m p p}$ at Gradients of 20,50,100 W/ $\mathrm{m}^{2} / \mathrm{s}$.

\section{Conclusions}

In this paper, a simple and accurate photovoltaic maximum power point tracking algorithm is proposed with its mathematical formulation. The Proposed MPPT algorithm is tested for its tracking speed, tracking accuracy, capability to rapid transition, and maximum power point efficiency and 
compared with the conventional hill climbing $P \mathcal{E} O$ method. The results show that the system reaches to MPP voltage in much fewer iterations and hence is very fast to converge to MPPs under fast-changing weather conditions. The duty cycle and maximum power point under various weather conditions have been analyzed also and compared with the $P \mathcal{E} O$ method. The results also show that the percentage of errors in finding duty cycles and maximum power points of the Proposed algorithm are much less than its counterpart ( $P \mathcal{E} O$ method). Subsequently, the developed algorithm was validated according to the CENELEC EN50530 standard which stipulates how the efficiency of the MPPT algorithm should be measured. It is also worthy of note that the Proposed algorithm does not require the technical specifications of the PV module as an input to the algorithm.

As a future work, the algorithm will be implemented using a micro-controller and other necessary hardware for a PV-Battery microgrid system and voltage stability will be studied for varying load conditions along with other control-algorithms such as fuzzy logic, artificial intelligence, model predictive control, etc. PV power ramp rate control also will be studied with the Proposed algorithm for high penetration level of PV systems as future smart grid applications.

Author Contributions: Conceptualization, A.D.; Funding acquisition, A.S.; Investigation, A.D.; Methodology, A.D.; Project administration, I.P.; Supervision, I.P. and A.S.; Writing-original draft, T.O.O.; Writing-review \& editing, T.O.O. and M.G.D. All authors have read and agreed to the published version of the manuscript.

Funding: This research was supported by National Science Foundation (NSF) under the grant number 1553494.

Conflicts of Interest: The authors declare no conflict of interest.

\section{References}

1. Olowu, T.O.; Sundararajan, A.; Moghaddami, M.; Sarwat, A.I. Future challenges and mitigation methods for high photovoltaic penetration: A survey. Energies 2018, 11, 1782. [CrossRef]

2. Jafari, M.; Olowu, T.O.; Sarwat, A.I.; Rahman, M.A. Study of Smart Grid Protection Challenges with High Photovoltaic Penetration. In Proceedings of the 2019 North American Power Symposium (NAPS), Wichita, KS, USA, 13-15 October 2019; pp. 1-6. [CrossRef]

3. Olowu, T.O.; Jafari, M.; Sarwat, A.I. A Multi-Objective Optimization Technique for Volt-Var Control with High PV Penetration using Genetic Algorithm. In Proceedings of the 2018 North American Power Symposium (NAPS), Fargo, ND, USA, 9-11 Septemper 2018; pp. 1-6. [CrossRef]

4. Olowu, T.O.; Sundararajan, A.; Moghaddami, M.; Sarwat, A.I. Fleet Aggregation of Photovoltaic Systems: A Survey and Case Study. In Proceedings of the 2019 IEEE Power Energy Society Innovative Smart Grid Technologies Conference (ISGT), Washington, DC, USA, 18-21 February 2019; pp. 1-5. [CrossRef]

5. Sundararajan, A.; Olowu, T.O.; Wei, L.; Rahman, S.; Sarwat, A.I. Case study on the effects of partial solar eclipse on distributed PV systems and management areas. IET Smart Grid 2019, 2, 477-490. [CrossRef]

6. Statistics, I.R.E. The International Renewable Energy Agency. July 2017. Available online: Http:/ / www. irena.org/-- /media/Files/IRENA/Agency/Publication/2017/ (accessed on 10 June 2020).

7. Fu, R.; Feldman, D.J.; Margolis, R.M. US Solar Photovoltaic System Cost Benchmark: Q1 2018; Technical Report; National Renewable Energy Lab. (NREL): Golden, CO, USA, 2018.

8. Rashid, K. Design, Economics, and Real-Time Optimization of a Solar/Natural Gas Hybrid Power Plant. Ph.D. Thesis, The University of Utah, Salt Lake City, UT, USA, 2019.

9. Alva, G.; Liu, L.; Huang, X.; Fang, G. Thermal energy storage materials and systems for solar energy applications. Renew. Sustain. Energy Rev. 2017, 68, 693-706. [CrossRef]

10. Rashid, K.; Safdarnejad, S.M.; Powell, K.M. Process intensification of solar thermal power using hybridization, flexible heat integration, and real-time optimization. Chem. Eng. Process.-Process Intensif. 2019, 139, 155-171. [CrossRef]

11. Sioshansi, R.; Denholm, P. The value of concentrating solar power and thermal energy storage. IEEE Trans. Sustain. Energy 2010, 1, 173-183. [CrossRef]

12. Debnath, A.; Huda, M.N.; Saha, C.; Roy, S. Determining Optimum Generator for South-East Coast of Bangladesh: Hybrid, Solar-Only or Wind-Only? In Proceedings of the 2018 10th International Conference on Electrical and Computer Engineering (ICECE), Dhaka, Bangladesh, 20-22 December 2018; pp. 165-168. 
13. Saha, C.; Huda, M.N.; Mumtaz, A.; Debnath, A.; Thomas, S.; Jinks, R. Photovoltaic (PV) and thermo-electric energy harvesters for charging applications. Microelectron. J. 2020, 96, 104685. [CrossRef]

14. Debnath, A.; Parvez, I.; Dastgir, M.; Nabi, A.; Olowu, T.O.; Riggs, H.; Sarwart, A. Voltage Regulation of Photovoltaic System with varying Loads. In Proceedings of the 2020 SoutheastCon, Raleigh, NC, USA, 10 March 2020; pp. 1-7.

15. Parvez, I.; Sarwat, A.; Debnath, A.; Olowu, T.; Dastgir, M.G. Multi-layer Perceptron based Photovoltaic Forecasting for Rooftop PV Applications in Smart Grid. In Proceedings of the 2020 SoutheastCon, Raleigh, NC, USA, 12-15 March 2020;

16. Shahriar, M.H.; Haque, N.I. ; Rahman, M.A.; Alonso Jr, M. G-IDS: Generative Adversarial Networks Assisted Intrusion Detection System. In Proceedings of the 2020 International Computer Software and Applications Conference (COMPSAC), Madrid, Spain, 13-17 July 2020; pp. 1-10.

17. Xiao, X.; Huang, X.; Kang, Q. A Hill-Climbing-Method-Based Maximum-Power-Point-Tracking Strategy for Direct-Drive Wave Energy Converters. IEEE Trans. Ind. Electron. 2016, 63, 257-267. [CrossRef]

18. Motsoeneng, P.; Bamukunde, J.; Chowdhury, S. Comparison of Perturb Observe and Hill Climbing MPPT Schemes for PV Plant Under Cloud Cover and Varying Load. In Proceedings of the 2019 10th International Renewable Energy Congress (IREC), Sousse, Tunisia, 26-28 March 2019; pp. 1-6. [CrossRef]

19. Du, X.; Yin, H. MPPT control strategy of DFIG-based wind turbines using double steps hill climb searching algorithm. In Proceedings of the 2015 5th International Conference on Electric Utility Deregulation and Restructuring and Power Technologies (DRPT), Changsha, China, 26-29 November 2015; pp. 1910-1914. [CrossRef]

20. Tan, C.Y.; Rahim, N.A.; Selvaraj, J. Improvement of hill climbing method by introducing simple irradiance detection method. In Proceedings of the 3rd IET International Conference on Clean Energy and Technology (CEAT) 2014, Kuching, Malaysia, 24-26 November 2014; pp. 1-5. [CrossRef]

21. Fatemi, S.M.; Shadlu, M.S.; Talebkhah, A. Comparison of Three-Point P O and Hill Climbing Methods for Maximum Power Point Tracking in PV Systems. In Proceedings of the 2019 10th International Power Electronics, Drive Systems and Technologies Conference (PEDSTC), Shiraz, Iran, 12-14 February 2019; pp. 764-768. [CrossRef]

22. Deopare, H.; Deshpande, A. Fuzzy based incremental conductance algorithm for PV system. In Proceedings of the 2016 International Conference on Automatic Control and Dynamic Optimization Techniques (ICACDOT), Pune, India, 9-10 September 2016; pp. 683-687. [CrossRef]

23. Ananthi, C.; Kannapiran, B. Improved design of sliding-mode controller based on the incremental conductance MPPT algorithm for PV applications. In Proceedings of the 2017 IEEE International Conference on Electrical, Instrumentation and Communication Engineering (ICEICE), Karur, India, 27-28 April 2017; pp. 1-6. [CrossRef]

24. Anowar, M.H.; Roy, P. A Modified Incremental Conductance Based Photovoltaic MPPT Charge Controller. In Proceedings of the 2019 International Conference on Electrical, Computer and Communication Engineering (ECCE), Cox'sBazar, Bangladesh, 7-9 February 2019; pp. 1-5. [CrossRef]

25. Vineeth Kumar, P.K.; Manjunath, K. Analysis, design and implementation for control of non-inverted zeta converter using incremental conductance MPPT algorithm for SPV applications. In Proceedings of the 2017 International Conference on Inventive Systems and Control (ICISC), Coimbatore, India, 19-20 January 2017; pp. 1-5. [CrossRef]

26. Kumar, N.; Hussain, I.; Singh, B.; Panigrahi, B.K. Framework of Maximum Power Extraction From Solar PV Panel Using Self Predictive Perturb and Observe Algorithm. IEEE Trans. Sustain. Energy 2018, 9, 895-903. [CrossRef]

27. Abdel-Salam, M.; El-Mohandes, M.T.; Goda, M. An improved perturb-and-observe based MPPT method for PV systems under varying irradiation levels. Sol. Energy 2018, 171, 547-561. [CrossRef]

28. Nedumgatt, J.J.; Jayakrishnan, K.B.; Umashankar, S.; Vijayakumar, D.; Kothari, D.P. Perturb and observe MPPT algorithm for solar PV systems-modeling and simulation. In Proceedings of the 2011 Annual IEEE India Conference, Hyderabad, India, 16-18 December 2011; pp. 1-6. [CrossRef]

29. Ahmad, J. A fractional open circuit voltage based maximum power point tracker for photovoltaic arrays. In Proceedings of the 2010 2nd International Conference on Software Technology and Engineering, San Juan, Puerto Rico, 3-5 October 2010; Volume 1, pp. 247-250. [CrossRef] 
30. Das, P. Maximum Power Tracking Based Open Circuit Voltage Method for PV System. Energy Procedia 2016, 90, 2-13. doi:10.1016/j.egypro.2016.11.165. [CrossRef]

31. Baimel, D.; Tapuchi, S.; Levron, Y.; Belikov, J. Improved Fractional Open Circuit Voltage MPPT Methods for PV Systems. Electronics 2019, 8, 321. [CrossRef]

32. Sher, H.A.; Murtaza, A.F.; Noman, A.; Addoweesh, K.E.; Chiaberge, M. An intelligent control strategy of fractional short circuit current maximum power point tracking technique for photovoltaic applications. J. Renew. Sustain. Energy 2015, 7, 013114. [CrossRef]

33. Husain, M.A.; Tariq, A.; Hameed, S.; Arif, M.S.B.; Jain, A. Comparative assessment of maximum power point tracking procedures for photovoltaic systems. Green Energy Environ. 2017, 2, 5-17. [CrossRef]

34. Sher, H.A.; Murtaza, A.F.; Noman, A.; Addoweesh, K.E.; Al-Haddad, K.; Chiaberge, M. A New Sensorless Hybrid MPPT Algorithm Based on Fractional Short-Circuit Current Measurement and P O MPPT. IEEE Trans. Sustain. Energy 2015, 6, 1426-1434. [CrossRef]

35. Youssef, A.; El Telbany, M.; Zekry, A. Reconfigurable generic FPGA implementation of fuzzy logic controller for MPPT of PV systems. Renew. Sustain. Energy Rev. 2018, 82, 1313-1319. [CrossRef]

36. Yang, B.; Zhong, L.; Zhang, X.; Shu, H.; Yu, T.; Li, H.; Jiang, L.; Sun, L. Novel bio-inspired memetic salp swarm algorithm and application to MPPT for PV systems considering partial shading condition. J. Clean. Prod. 2019, 215, 1203-1222. [CrossRef]

37. Rizzo, S.A.; Scelba, G. ANN based MPPT method for rapidly variable shading conditions. Appl. Energy 2015, 145, 124-132. [CrossRef]

38. Motahhir, S.; El Hammoumi, A.; El Ghzizal, A. The Most Used MPPT Algorithms: Review and the Suitable Low-cost Embedded Board for Each Algorithm. J. Clean. Prod. 2019. [CrossRef]

39. Wilson, K.R.; Rao, Y.S. Comparative Analysis of MPPTT Algorithms for PV Grid Tied Systems: A Review. In Proceedings of the 2019 2nd International Conference on Intelligent Computing, Instrumentation and Control Technologies (ICICICT), Kannur, India, 5-6 July 2019; Volume 1, pp. 1105-1110.

40. BP SX 150. Available online: https:/ / www.abcsolar.com/pdf/bpsx150.pdf/ (accessed on 12 June 2020).

41. Kamran, M.; Mudassar, M.; Fazal, M.R.; Asghar, M.U.; Bilal, M.; Asghar, R. Implementation of improved Perturb \& Observe MPPT technique with confined search space for standalone photovoltaic system. J. King Saud Univ.-Eng. Sci. 2018. doi.org/10.1016/j.jksues.2018.04.006. [CrossRef]

42. Andrejašič, T.; Jankovec, M.; Topič, M. Comparison of direct maximum power point tracking algorithms using EN 50530 dynamic test procedure. IET Renew. Power Gener. 2011, 5, 281-286. [CrossRef]

43. Bründlinger, R.; Henze, N.; Häberlin, H.; Burger, B.; Bergmann, A.; Baumgartner, F. prEN 50530-The new European standard for performance characterisation of PV inverters. In Proceedings of the 24th EU PV Conference, Hamburg, Germany, 21-25 September 2009. 